\title{
The Internal Relatedness of All Things
}

\author{
JONATHAN SCHAFFER \\ Australian National University \\ jonathan.schaffer@anu.edu.au
}

The argument from internal relatedness was one of the major nineteenth century neo-Hegelian arguments for monism. This argument has been misunderstood, and may even be sound. The argument, as I reconstruct it, proceeds in two stages: first, it is argued that all things are internally related in ways that render them interdependent; second, the substantial unity of the whole universe is inferred from the interdependence of all of its parts. The guiding idea behind the argument is that failure of free recombination is the modal signature of an integrated monistic cosmos.

Frequently consider the connection of all things in the uni-
verse and their relation to one another. For in a manner all
things are implicated with one another...

(Marcus Aurelius, Meditations, p. 43)

Many of us were raised to believe the following story. By the end of the nineteenth century, darkness was over the surface of the deep. Philosophy was dominated by neo-Hegelian monistic idealism, and plunged into obscurity and confusion. And then there was light. As the twentieth century dawned, Russell and Moore separated from the neo-Hegelians by defending external relations, pluralism, realism, clarity, and all that is Good.

The creation myth of analytic philosophy - like many founding myths - contains some traces of truth. By the end of the nineteenth century, philosophy was indeed dominated by neo-Hegelian monistic idealism. Russell and Moore did indeed separate from the neo-Hegelians by defending external relations, pluralism, and realism. Russell and Moore were much clearer than their predecessors, and this was Good. But the neo-Hegelians actually had an argument for their monism - the argument from internal relatedness - which went misunderstood, and which may even be sound. Or so I will argue.

Overview of the argument: The argument from internal relatedness, as I will reconstruct it, proceeds in two stages. First, it is argued that all 
things are internally related in ways that render them interdependent. Second, the substantial unity of the whole universe is inferred from the interdependence of all of its parts. Overall the argument runs from universal internal relatedness to priority monism. The guiding idea is that failure of free recombination is the modal signature of an integrated monistic cosmos.

Overview of the paper: In section 1, I will clarify the key concepts of monism, priority, internal relatedness, and free recombination. In section 2, I will consider the second stage of the argument - from universal internal relatedness to monism - and provide some proofs. In section 3, I will turn to the first stage of the argument - that all things are internally related - and show how some plausible contemporary views vindicate this claim. I will conclude in section 4 by considering how the pluralist might respond.

\section{Clarifications}

\subsection{Monism: the priority of the whole}

I begin with a clarification of the monistic view at issue. The monistic view is now almost universally thought to be a world-only view, on which the world is the only thing that exists (Hoffman and Rosenkrantz 1997, p. 78; van Inwagen 2002, p. 25; inter alia). On such a view there are no particles, pebbles, planets, or any other proper parts to the world. There is only a seamless Parmenidean whole.

Yet the core thesis of classical monism is that the whole is prior to its parts. Such a thesis presupposes that the whole has parts, for the whole to be prior to them. This suggests not a world-only view but rather a world-first view (or at least a world-before-parts view). On such a view, particles, pebbles, and planets all exist, but are secondary to the whole cosmos in the order of dependence. In this light, consider Proclus' dictum: ' $[\mathrm{T}]$ he monad is everywhere prior to the plurality... In the case of bodies, the whole that precedes the parts is the whole that embraces all separate beings in the cosmos' (Comm., p. 79).

Moreover, a leading slogan of classical monism is the organic unity of the whole. The notion of organic unity comes from Aristotle's view of the organism as a substantial whole, whose limbs, organs, and other sundry parts are dependent on their integration within the whole. Speaking of the world as having organic unity presupposes that the world has proper parts, to be the limbs and organs (as it were) of the cosmic body. Again, this suggests not a world-only view but a 
world-first view, with the proper parts essentially playing certain roles in the whole. In this light, consider the words of Plotinus (echoing Plato in Timaeus): 'All is one universally comprehensive living being, encircling all the living beings within it,... every separate thing is an integral part of this All by belonging to the total material fabric...' (Enn., pp. 318-19). Or as Hegel memorably writes:

The limbs and organs for instance, of an organic body are not merely parts of it: it is only in their unity that they are what they are,... These limbs and organs become mere parts, only when they pass under the hands of an anatomist, whose occupation be it remembered, is not with the living body but with the corpse. (1817, pp. 191-2)

In any case, the monistic view at issue is supposed to be motivated by an argument from the internal relatedness of all things. Such an argument presupposes that the world has proper parts, to be the things internally related. Yet again this suggests not a world-only view but a world-first view, with the proper parts being interconnected in ways that reveal their interdependence. In this light, consider Marcus Aurelius's injunction: 'Frequently consider the connection of all things in the universe and their relation to one another. For in a manner all things are implicated with one another' (Med., p. 43). Or as Royce declares:

If ... we should find that, within the realistic world, all the real objects there present were in any way linked together, so as not to be mutually independent, we should so far have ... to regard them as parts or aspects of One real being. (1900, p. 122)

So here is the first respect in which the argument from internal relatedness has been misunderstood: the monistic view at issue is not a world-only view but a world-first view. The world-first view at issue is what I have elsewhere (Schaffer 2007, 2010) called priority monism. Priority monism is a claim about the dependence ordering among concrete objects, to the effect that the whole comes first and its proper parts come second. The parts are posterior to, grounded in, dependent upon, and existent in virtue of, the whole.

A more precise formulation can be given by introducing the property of being a basic concrete object, in the sense of being a concrete object not dependent on any concrete object (more on the relevant notion of dependence in Sect. 1.2). Letting ' $B$ ' denote this property:

(Basic concrete $\quad \mathrm{B} x=_{d f}(\mathrm{i}) x$ is a concrete object, and (ii) there is no $y$ object) such that (a) $y$ is a concrete object, and (b) $x$ depends on $y$ 
Priority monism is then the claim that there is exactly one basic concrete object, and it is the whole world. Letting ' $u$ ' denote the whole concrete cosmos:

\section{(Priority monism) $\quad(\exists ! x) \mathrm{B} x \& \mathrm{~B} u^{1}$}

Priority monism may be contrasted with the priority nihilist view that nothing is a basic concrete object, and with the priority pluralist view that there are two or more basic concrete objects:

$$
\begin{array}{ll}
\text { (Priority nihilism) } & \neg(\exists x) \mathrm{B} x \\
\text { (Priority pluralism) } & (\exists x)(\exists y)(\mathrm{B} x \text { \& By \& } x \neq y)^{2}
\end{array}
$$

So much for what priority monism is. It is worth (re-)emphasizing that priority monism is not a world-only view. Nor is it the view that the world is fundamental. The claim that whole is prior to part is only a claim about the dependence ordering amongst concrete objects, and is neutral on how concrete objects stand with respect to further entities such as properties and abstract objects. ${ }^{3}$ Nor is priority monism a modal claim. As formulated it is only a claim about actuality. Most classical monists would go further and maintain that the priority of the whole holds with metaphysical necessity. Whether the argument from internal relatedness supports this stronger modal claim depends on the modal status of the premisses (I will return to this in Sect. 4).

The monistic view at issue in the argument from internal relatedness is priority monism. Never mind the label. If you doubt that the view at issue deserves to be called 'monism', call it something else. Never mind the history. If you doubt that that the classical monists endorsed this view, call it a new proposal. Just understand the content

\footnotetext{
${ }^{1}$ This definition does not directly say that the proper parts (e.g. the particles, pebbles, and planets) depend on the whole cosmos. But given that the proper parts exist, the definition of priority monism entails that they are not basic. Their dependence on the cosmos then follows given that (i) what is not basic is dependent, and (ii) what is dependent depends on what is basic (these are respective consequences of the definition of basicness and of the well-foundedness requirement: Sect. 1.2).

2 These distinctions are exclusive but not exhaustive. There remains room in logical space for the view that there is exactly one basic concrete object, but it is something short of the whole world (e.g. my nose). To rule this out would require the further thesis that the basic objects must collectively cover the whole of reality by having the whole concrete cosmos as their sum. (This is a part of 'the tiling constraint' in Schaffer 2010, Sect. 1.3.)

${ }^{3}$ To get from priority monism to the view that the world is fundamental, one must add a things-first thesis, on which concrete objects are prior to any other entities. I happen to endorse this thesis (Schaffer 2009a, pp. 378-9, labelled 'thick particularism'). But one can be a priority monist and be a trope-first theorist (Campbell 1990, p. 154), or an abstracta-first theorist (Plato Rep., p. 744; Plotinus Enn., p. 361), inter alia.
} 
of the proposal: the whole concrete cosmos is prior to its particles, pebbles, planets, and other proper parts.

\subsection{Priority: metaphysical structure}

The monistic view at issue - namely, priority monism - makes crucial use of the notion of priority. So it may help to say more about this notion. To begin with, the notion of priority in play is not the causal notion on which effect depends on cause, nor is it the conceptual notion on which analysandum depends on analysans. It is rather the metaphysical notion on which one entity depends on another for its nature and existence. Anyone who wants to recognize that some things are fundamental and some things derivative needs some such notion. This is the notion that Plato famously invokes in the Euthyphro dilemma, asking 'Is what is holy holy because the gods approve it, or do they approve it because it is holy?' (Euth., p. 178), ${ }^{4}$ and the notion that Aristotle codifies as priority in nature (Meta., p. 1609).

To illustrate, consider the existence of Socrates and the truth of the proposition $<$ Socrates exists $>$. Though both facts obtain at exactly the same worlds, the former is clearly prior - the truth obtains because the man exists, not vice versa (Aristotle Cat., p. 22). Or consider the existence of Socrates (a fact) and Socrates himself (an object). Though the fact obtains at exactly the same worlds where the object is found, the object is arguably prior - the fact about the object obtains in virtue of the object. Or consider Socrates himself alongside his singleton, \{Socrates\}. Though both objects exist at exactly the same worlds, Socrates seems prior - the singleton is founded upon its member (Fine 1994a, p. 271).

The above illustrations feature fact-fact, object-fact, and objectobject priority relations. For an illustration of property-property priority, consider Socrates's mental and neural properties. The neural properties are now widely regarded as prior - mental properties are instantiated on the basis of neural properties. For object-property priority, consider Socrates's neural properties and Socrates himself. Socrates is arguably prior - Socrates's properties are dependent modifications of Socrates himself (Descartes 1644, p. 196; Armstrong 1997, p. 99). For an object-object case involving whole and part, consider Socrates alongside his limbs and organs. Which is prior in this case?

\footnotetext{
${ }^{4}$ Plato also invokes this notion in Republic, when explaining the relation of the sensibles to the forms, and of all other forms to the form of the good: '[T]he objects of knowledge not only receive from the presence of the good their being known, but their very existence and essence is derived to them from it,...' (Rep., p. 744).
} 
A hard question! According to Aristotle at least, Socrates is prior, with the many parts of his body being what they are in virtue of their integration in the whole. The classical monist views the world this way (Sect. 1.1).

Priority, so understood, turns out to be theoretically crucial to understanding physicalism, truthmaking, and the general Armstrong-Lewis program of sparse ontology, inter alia. Physicalism is the view that the mental and moral depend on the physical. Thus Loewer maintains: 'the fundamental properties and facts are physical and everything else obtains in virtue of them' (2001, p. 39). Truthmaking is the relation by which truth depends on being. Thus Armstrong motivates truthmaking by asking (1997, p. 115): 'Must there not be something about the world that makes it to be the case, that serves as an ontological ground, for this truth?' And sparse ontology concerns what Campbell describes as 'the ontic constitution of the cosmos' (1990, pp. 24-5), the ultimate grounds on which all else depends. ${ }^{5}$

More formally, and restricting attention to the first-order (since dependencies between individuals are all that will be at issue here), one can introduce a two-place relation of ontological dependence: Dxy (to be read ' $x$ depends on $y$ '). Dependence is understood to be an irreflexive, transitive, and well-founded relation. ${ }^{6}$ Formally this can be modelled by a directed acyclic graph, on which every path has a source. As an irreflexive and transitive relation, dependence induces a partial ordering over the entities in its field - the tree of being. As a well-founded relation, dependence identifies the fundamental entities on which all else depends - the roots of being.

Starting from dependence, a family of further metaphysical structuring concepts may be defined. Here I assume the conceptual resources of first-order logic plus classical mereology (though weaker mereological systems will suffice - see Sect. 2) on a domain of actual concrete

\footnotetext{
${ }^{5}$ Indeed the idea of sparse ontology traces back to Aristotle's conception of metaphysics as the science which studies the substances, where substances are the basic independent units of being: 'Substance is the subject of our inquiry; for the principles and the causes we are seeking are those of substances. For if the universe is of the nature of a whole, substance is its first part' (Meta., p. 1688). In Aristotelian terms, the question of monism is the question of whether the whole cosmos is a single unified substance, or a mere heap.

6 Though it will turn out that the argument will go through with an anti-symmetric, transitive, and well-founded conception of dependence (see Lowe 2005 for an anti-symmetric view of dependence). This will require a natural modification to the definition of basicness below, to allow for self-dependence: $x$ is basic $^{\star}=_{d f} \neg(\exists y)(x \neq y \& \mathrm{D} x y)$. In section 2.2 I appeal to asymmetry in one line of the main argument, and will explain there how anti-symmetry (coupled with the modified notion of basicness) is sufficient for the argument.
} 
objects. I use ' $<$ ' for part, ' $\ll$ ' for proper part, and 'O' for overlap. (Note: All quantifiers here are restricted to actual concrete objects.)

$$
\begin{aligned}
\text { (Basicness) } & x \text { is basic }=_{d f} \neg(\exists y) \text { D } x y \\
& x \text { does not depend on anything } \\
& \text { (equivalent to B (Sect. 1.1), given the quantifier } \\
& \text { restrictions now in place) } \\
\text { (Fragmentedness) } & x \text { is a fragment }=_{d f}(\exists y)(\mathrm{D} x y \& x \ll y) \\
& x \text { depends on one of its proper wholes } \\
\text { (Organic unity) } \quad & x \text { is an organic unity }=_{d f}(\exists y) y \ll x \& \\
& (\forall y)(y \ll x \rightarrow \mathrm{D} y x) \\
& x \text { has proper parts, and all of its proper parts } \\
& \text { depend on it } \\
\text { (Mere heap) } \quad & x \text { is a mere heap }=_{d f}(\exists y) y \ll x \& \\
& (\forall y)(y \ll x \rightarrow \text { D } x y) \\
& x \text { has proper parts, and depends on all of its } \\
& \text { proper parts } \\
\text { (Interdependence) } \quad & x \text { and } y \text { are interdependent }=_{d f} x \neq y \text { \& } \\
& (\exists z)(\mathrm{D} x z \& \text { D } y z \& x \ll z \& y \ll z) \\
& x \text { and } y \text { are non-identical and co-dependent on } \\
& \text { a common whole }
\end{aligned}
$$

This is hardly an exhaustive list of metaphysical structuring concepts, but only an attempt to illustrate the fruitfulness of the notion of dependence.

I have not tried to analyse ontological dependence. By my lights (Schaffer 2009a) dependence is the primitive structuring concept of metaphysical inquiry - one should not expect to find any concept deeper. But perhaps dependence can be analyzed in terms of essences (Fine 1994a, Lowe 2005), supervenience (Lewis 1994, Bricker 2006), or in some other terms. For present purposes all that I require - as a condition of adequacy on any treatment of dependence - is that it preserve the formal structure and definitions given above.

I have also treated dependence as objective, but it can in principle be relativized to one's practical interests or theoretical scheme or something like that, if one is so inclined. Thus one can invoke a three-place relation $\mathrm{D} x y z$, to be read as ' $x$ depends on $y$ for subject $z$ '. The formal principles will then be required to hold for fixed $z$. So for instance the extended 'transitivity' principle will run:

$$
\left(\forall x_{1}\right)\left(\forall x_{2}\right)\left(\forall x_{3}\right)(\forall z)\left(\left(D x_{1} x_{2} z \& D x_{2} x_{3} z\right) \rightarrow D x_{1} x_{3} z\right)
$$


The definitions will then be relativized to $z$. So the extended definition of basicness will run: $x$ is basic for $z$ iff $\neg(\exists y) \mathrm{D} x y z$. All the arguments to follow should still go through (I leave this as an exercise to the reader). If you think that dependence is relative to one's theoretical scheme, you might still be interested in which theoretical schemes yield the pluralistic image of a scattering of dust, and which lead to the monistic image of a unified cosmos.

\subsection{Internal relatedness}

It remains to clarify the notion of internal relatedness in use. For many of us today the first conception of internal relatedness that will spring to mind is Lewis's notion of a relation intrinsic to its relata. Thus Lewis (1986, p. 62) defines a notion that I will label 'internal intrinsic' $_{\text {' }}$ as follows:

$$
\begin{array}{ll}
\text { (Internal } \left._{\text {intrinsic }}\right) \quad \mathrm{R} \text { is internal } \\
\\
\text { then }\left(\forall y_{1}\right) \ldots\left(\forall y_{n}\right)\left(\text { if } y_{1} \text { is a duplicate of } x_{1}\right. \\
\text { and } \left.\left.\ldots \text { and } y_{n} \text { is a duplicate of } x_{n} \text {, then } R y_{1} \ldots y_{n}\right)\right)
\end{array}
$$

The root idea of a relation being internal ${ }_{\text {intrinsic }}$ may be expressed as follows: duplicate the relata, and you duplicate the relation.

The Lewisian notion of an internal ${ }_{\text {intrinsic }}$ relation is perfectly coherent. Only it is not the notion at work in the argument from internal relatedness. Indeed it is trivial that everything in the universe is internally $y_{\text {intrinsic }}$ related. First example: take any two things, they will resemble in some respect $r$, to some degree $d$. Duplicate both things, and the duplicates will equally resemble in respect $r$ to degree $d$. There is universal internal ${ }_{\text {intrinsic }}$ relatedness! Second example: take a relation that holds between any two things, such as being either identical or different. Any two things will stand in this trivial relation, and so a fortiori their duplicates will also stand in this relation. There again is universal internal ${ }_{\text {intrinsic }}$ relatedness! Only there is no way - or at least none that I can see - to extract the organic unity of the cosmos from that.

So what notion of internality did the neo-Hegelians and early analytics have in mind? Unfortunately there may be no determinate answer. Though the debate centred on internal relatedness, it seems that neither side had a fixed and clear understanding of this key notion. Thus Ewing (1934, Ch. 2) distinguishes ten different senses in which the term was used on both sides. I suspect this may be an undercount. Indeed Church (1935) complains that Bradley's conception of 'internal relation' is off Ewing's list. 
Still I think that there was one dominant sense of the notion, according to which an internal relation is essential to its relata. This is Ewing's second sense, invoked implicitly by Bradley (1897, p. 347) ${ }^{7}$ and Bosanquet (1911, p. 277), and explicitly by Moore (1919, p. 47), Blanshard (1939, p. 452), and Rorty (1967, p. 125). I will label this 'internal essential $_{\text {': }}$

(Internal $\left._{\text {essential }}\right) \quad \mathrm{R}$ is internal essential $_{d f}\left(\forall x_{1}\right) \ldots\left(\forall x_{n}\right)$ if $\mathrm{R} x_{1} \ldots x_{n}$ then necessarily $\left(\left(x_{1}\right.\right.$ exists $\left.\leftrightarrow \mathrm{R} x_{1} \ldots x_{n}\right)$ $\& \ldots \&\left(x_{n}\right.$ exists $\left.\left.\leftrightarrow \mathrm{R} x_{1} \ldots x_{n}\right)\right)^{8}$

If everything is internally $y_{\text {essential }}$ related (which is hard to swallow), the monistic conclusion will indeed follow. Everything will be interdependent in a very strong sense - if one thing were to fail to exist, then everything would fail to exist. ${ }^{9}$ But I think the monistic conclusion will equally follow from a much less demanding conception of internal relatedness.

To illustrate, begin from the supposition that you and I are in the same room, and that being in the same room is a binary internal ${ }_{\text {essential }}$ relation. Then we are essentially room-mates - in every world where you exist, I exist in the same room; and in every world where I exist, you exist in the same room. (Impossible to be rid of me!) But now suppose that instead of having the essential relational property of being room-mates with me, you merely have the essential relational property of being room-mates with someone else. In every world where you exist, someone else exists in the same room with you. (Impossible to be alone!) There is no particular someone else to whom you are essentially related. Yet still there is a clear sense in which you have a relational essence that points beyond you, and hooks you into the wider world. In this sense you cannot be a basic independent unit

\footnotetext{
7 Bradley himself (idiosyncratic as always) was not a proponent of the argument from internal relatedness, since he did not accept the reality of any relations, internal or external. Indeed, Bradley labelled it 'ludicrous' and 'an obvious, if perhaps a natural mistake' to take his denial of the reality of external relatedness as advocacy of internal relatedness (1935, pp. 642-3; cf. Ewing 1935).

${ }^{8}$ I have rendered an essence claim in terms of a necessity claim. This is problematic in two respects. First, when I come to consider counterpart theory (Sect. 3.4), the consequences of using the modal language will differ from the consequences of using a quantifier over worlds (e.g. replacing the box with a universal quantifier over worlds, and appending 'at $w$ ' to each of the biconditions conjoined after 'necessarily'). Second, one might think essence claims are strictly stronger than any modal claims (Fine 1994b). But it is generally granted that the essence claim will still entail the modal claim, and that is all I need here.

${ }^{9}$ Such a claim is reminiscent of what Spinoza wrote to Oldenburg: 'if one particle of matter be annihilated, the whole of Extension would forthwith vanish' (1966, p. 69).
} 
of being, since you are dependent on the rest of the world to accommodate your needs. (You need a room-mate!) You cannot for instance be placed alone in a room.

The key idea emerging is that of standing the Humean principle of free recombination on its head. If there really were multiple basic independent units of being, they would be (in Hume's words) 'entirely loose and separate' (1748, p. 54), and so should be freely recombinable in any which way. Given that there are no necessary connections between distinct existents, necessary connections show that the existents in question are not distinct. A disconnected pluralistic heap should be amenable to free recombination; failure of free recombination is thus the modal signature of an interconnected monistic cosmos. In short: while the neo-Humean argues from pluralism to free recombination, the neo-Hegelian should argue from failure of free recombination to monism.

So here is the second respect in which the argument from internal relatedness has been misunderstood: many senses of 'internal relation' have been in play (on both sides of the debate), and no one (on either side) seems to have tried to reverse engineer the minimal sense of 'internal relation' sufficient for the monistic conclusion. With such a reverse engineering project in mind, I propose to work with the notion of a modally constraining relation, which is a relation that precludes the free recombination of its relata. So, letting ' $\mathrm{M}^{n}$ ' be the $n$-ary relation of modal freedom (more on this in Sect. 1.4), one can define an internal $_{\text {constraining }}$ relation as per:

$$
\begin{array}{ll}
\text { (Internal } \left._{\text {constraining }}\right) & \mathrm{R} \text { is internal } \mathrm{l}_{\text {constraining }}=d f \\
& \left(\forall x_{1}\right) \ldots\left(\forall x_{n}\right) \text { if } \mathrm{R} x_{1} \ldots x_{n} \text { then } \neg \mathrm{M}^{n} x_{1} \ldots x_{n}{ }^{10}
\end{array}
$$

To a zero-eth approximation and sticking to the binary case, $\mathrm{M}^{2} x_{1} x_{2}$ obtains iff any way $x_{1}$ can be, and any way $x_{2}$ can be, constitutes a combined way that both $x_{1}$ and $x_{2}$ can be. Modally free entities are like

\footnotetext{
${ }^{10}$ Problem: if everything is internally related at every world, then every relation comes out internal, since $\neg \mathrm{M}^{n} x_{1} \ldots x_{n}$ always holds. The fix is to complicate the definition to include an 'in virtue of' relation:

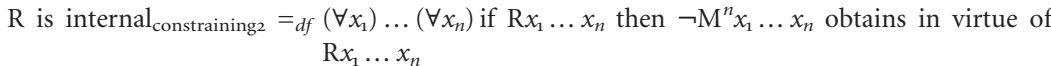

But this added complication does not matter for the argument. For if everything is internally related at every world, then the monistic conclusion will follow whether (a) all relations get counted as internal, as the definition in the main text rules, or (b) only some relations get counted as internal as the more complex variant rules. (What does matter for the argument is maintaining Assumption 1: Sect. 2.1.) So in the main text I will work with the simpler formulation.
} 
multiple knobs on a stereo. There are no necessary connections between the setting of the one knob and the other. Any way the one knob can be set, and any way the other knob can be set, is a way both knobs can be set. All combinations are possible. ${ }^{11}$

Before I try to clarify the notion of modal freedom further, I would just note that there are hints of something like the notion of intern$\mathrm{al}_{\text {constraining }}$ relatedness in the literature. Royce speaks of a relation through which things fail to be 'mutually independent' (1900, p. 122), Baylis says that the principle of internal relatedness is best understood as 'the principle of partial interdependence' (1929, p. 375), and Joachim glosses Spinozistic monism in terms of an interwoven dependence:

A single 'extended' thing — a particular body e.g. — is finite and dependent; a fragment torn from its context, in which alone it has its being and significance. Neither in its existence nor in its nature has it any independence. It owes its existence to an indefinite chain of causes, each of which is itself a finite body and the effect of another finite body; it owes its nature to its place in the whole system of bodies which together constitute the corporeal universe. (1901, p. 23)

It should be acknowledged, however, that internal ${ }_{\text {constraining }}$ corresponds to none of Ewing's ten senses of 'internal.' So in this respect I may be offering a new variant of the monistic argument.

\subsection{Modal freedom}

The notion of internal relatedness at issue - namely, internal ${ }_{\text {constraining }}$ relatedness - makes crucial use of the relation of free recombination. It is difficult to define this notion precisely. ${ }^{12}$ Fortunately this will not be necessary for what follows - all that will be necessary is to sketch a necessary condition clear enough for later use, for two entities to be

${ }^{11} \mathrm{M}^{2}$ is understood to be an irreflexive, symmetric, and non-transitive relation. Irreflexivity: $\mathrm{M}^{2} a a$ cannot hold, as there is a necessary equality between how $a$ is, and how $a$ is. Symmetry: $\mathrm{M}^{2} a b$ and $\mathrm{M}^{2} b a$ impose exactly the same requirements, namely that all $a-b$ combinations are possible. Non-transitivity: if $a$ and $c$ are constrained to be the same color, but neither has any connection with $b$, then $\mathrm{M} a b \& \mathrm{M} b c$ but $\neg \mathrm{M} a c$.

${ }^{12}$ For instance, Lewis - perhaps the foremost defender of free recombination - offers only the following gloss: 'Roughly speaking, the principle is that anything can coexist with anything else, at least provided they occupy distinct spatiotemporal positions. Likewise, anything can fail to coexist with anything else' (1986, p. 88). This rough statement does not consider whether the one thing would need to be altered so as to coexist, or fail to coexist, with the other. Nor does it consider whether there are only specific spatiotemporal configurations the two things must be in, beyond distinctness of position. For more on the Lewisian notion - and how it differs from the notion I am using - see Sect. 3.4. 
modally free of each other. (This later use will consist in arguing that no two things are modally free: Sects. 3.2-3.4.)

The intuitive idea I will use is that modal freedom requires no necessary connections between two entities. How, where, or whether the first entity is should place no constraints on how, where, or whether the second entity is. This idea may be further articulated as follows:

If $\mathrm{M}^{2} x y$ then: for any way that $x$ can be, and for any way that $y$ can be, there is a metaphysically possible world $w$ in which $x$ and $y$ are each these respective ways (barring co-location, and leaving the rest of the world as is).

Now to the unpacking: Starting with 'for any way that $x$ can be' and 'for any way that $y$ can be', consider all of the intrinsic natures that a given actual concrete object can have, together with all of the spatiotemporal locations that it can occupy. These are the ways that this object can be. Also add in the one way that it can fail to be. The result will be a list covering the how, where, and whether possibilities for this thing. To illustrate, imagine that there are only two natures that a given thing a can have, being red and being blue. And imagine that there are only two locations that $a$ can occupy, here and there. Then there are four ways that $a$ can be, plus the one way that $a$ can fail to be. Collecting these into the set of ways for $a, W_{\mathrm{a}}$ :

$W_{a}=\{a$ is red and here, $a$ is red and there, $a$ is blue and here, $a$ is blue and there, $a$ does not exist $\}$

What is then required is that 'there is a metaphysically possible world $w$ in which $x$ and $y$ are each these respective ways'. This is the requirement of compossibility. Where $W_{x}$ is the set of ways $x$ can be, and $W_{y}$ is the set of ways that $y$ can be, the requirement (to be amended below) is that there be a world realizing every pair of ways in the product set $W_{x} \times W_{y}$. For instance, supposing that a given thing $a$ has the five possibilities given by $W_{a}$ above, and that $b$ has the parallel five possibilities, then there will be twenty-five combination pairs in the product set:

$W_{a} \times W_{b}=\{<a$ is red and here, $b$ is red and here $>,<a$ is red and here, $b$ is red and there $>, \ldots,<a$ does not exist, $b$ does not exist $>$ \}

What is required (to be amended below) is that there be a world which realizes every combination pair. This is the idea that the entities are like two knobs on a stereo, in the sense that all combinations are possible. More precisely, the idea is that if there is a combination pair such as $<a$ is red and here, $b$ is blue and there $>$ which lacks a realizing world, then $a$ and $b$ would fail to be modally free of each 
other - $a$ 's being red and here would impose a modal constraint on $b$, precluding $b$ from being blue and there. ${ }^{13}$

Two amendments are then added to complete this requirement, the first of which is 'barring co-location'. For one might think that non-identical concrete objects cannot co-locate (Locke 1690, p. 134). If so then one should impose a global constraint on recombination, to the effect that realizing worlds are only required for the combination pairs in the product set that do not involve the co-location of non-identicals. ${ }^{14}$ With the example of $a$ and $b$ given above, this first amendment has the effect of removing the requirement of a realizing world in the eight combination pairs that would call for co-location (such as $<a$ is red and there, $b$ is blue and there $>$, and so only requiring realizing worlds for the remaining seventeen combinations. (Actually I think that the philosopher who holds that non-identical concrete objects cannot co-locate has already upheld a real constraint on modal freedom. She has already declared that all concrete objects are relationally connected as occupants of a common space-time system, in a way that imposes global constraints. ${ }^{15}$ Just like someone who has the essential relational property of being room-mates with someone else requires the rest of the world to accommodate her needs, so an object that has the essential relation property of not being placemates with anything else requires the rest of the world to accommodate its needs. But I do not wish to insist on this point here. So I will allow the philosopher who thinks that non-identical concrete objects cannot co-locate to restrict the requirement on modal freedom, rather than immediately charging her with being committed to universal internal relatedness.)

\footnotetext{
13 On certain views of modal discourse, such as counterpart theory, the requirement of a realizing world must be distinguished from the requirement of a representing world. The realizing world is one at which the combination obtains. The representing world is one that merely (at a given context) represents the combination as obtaining. I will return to this distinction in Sect. 3.4.

${ }^{14}$ In effect this is what Lewis is getting when he says 'anything can coexist with anything else, at least provided they occupy distinct spatiotemporal positions' (1986, p. 88, italics added). I should mention that Lewis - for reasons that are largely internal to his modal realism, and in ways that do not arise when just looking at recombination for pairs of actual objects imposes two further restrictions on general free recombination. First, he requires that the combination involves a maximally spatiotemporally connected scenario. Second, he requires that the combination not involve too many individuals or spatiotemporal dimensions (his 'size and shape permitting' proviso).

15 In a somewhat related vein, Bosanquet speaks of internal relations which involve 'a community of kind', giving the example: 'You cannot have a spatial relation between terms which are not in space' (1911, p. 277).
} 
The second and final amendment reads 'leaving the remainder of the world as is'. The intuitive idea is that if two actual concrete objects really are modally free of each other, then realizing their combinations should not require alterations to anything distinct. By 'the remainder of the world' I mean the concrete universe minus the sum of the two objects in question, and by 'leaving it as it is' I mean preserving its intrinsic nature and spatiotemporal location, while not adding in any alien properties or individuals. What is required is that the worlds realizing the combination pairs for the two entities in question leave the remainder of the world as is. To illustrate, suppose that $a$ and $b$ are mereological atoms, and that just one other atom $c$ exists (and no gunk), where $c$ is green and yonder. Then the requirement is that the realizing worlds for the combination pairs in $W_{a} \times W_{b}$ all be worlds in which $c$ remains green and yonder, and in which nothing further is added. Intuitively, one should not have to vary $c$ or add anything further to recombine $a$ and $b .^{16}$ (These requirements interact. If one is considering whether $a$ and $b$ are freely recombinable, and $a$ can be at a location already occupied by something in the remainder, then none of the combination pairs involving this way that $a$ can be should require a realization world. For this would call for co-location of non-identicals again. This interaction did not arise in the example I have been working with, but would have if for instance $b$ had been allowed to occupy the location yonder which $c$ already occupies.)

Putting this together, the necessary condition that I will be using for modal freedom works as follows. Take any two entities, draw up the set of possibilities for each entity, and take the product of these two sets. Now require of each member of the product set that it has a realization in which the remainder of the world is left as is, unless that would require co-location (in which case impose no requirement for that member of the product set). If we do not find the required range of realizing worlds, infer $\neg \mathrm{M}^{2} a b$.

Identity and mereological overlap may serve as illustrative cases of internal $_{\text {constraining }}$ relations, which entail $\neg \mathrm{M}^{2} a b$. With identity, obviously a given entity $a$ cannot be freely recombined with itself. There are ways that $a$ can be, and ways that $a$ can be, that are not compossible (barring co-location, and ignoring worlds with alien individuals

\footnotetext{
16 This amendment might also be thought of as deriving from the requirement of modal freedom in the ternary case between two given entities $a$ and $b$, and $c=u-(a+b)$. Given that one way that $c$ can be is to be exactly as it actually is, this amendment is effectively looking to those combination triples for $a, b$, and $c$ in which $c$ is as it actually is, and requiring that at least this aspect of $\mathrm{M}^{3} a b c$ hold in order for $\mathrm{M}^{2} a b$ to hold.
} 
or properties). For instance, $a$ cannot be red and here at a world where $a$ does not exist. So if $a=b$ then $\neg \mathrm{M}^{2} a b$. With overlap, let $c$ be a part common to $a$ and $b$. Then $a$ cannot retain the property of having $c$ as a part and being here, while $b$ retains the property of having $c$ as a part but moves there (given that $c$ cannot multi-locate, or at least that multi-location of concrete objects is alien). So if $\mathrm{O} a b$ then $\neg \mathrm{M}^{2} a b$.

Things that are identical or that overlap are thus internally ${ }_{\text {constraining }}$ related. This is a plausible result, and confirms that our necessary condition for modal freedom is off to a plausible start. In section 3, I will argue that several contemporary metaphysical views entail that everything is internally $y_{\text {constraining }}$ related. This will be the key claim of the first stage of the monistic argument.

\section{Stage two: from universal internal relatedness to monism}

Having clarified the key concepts in use, I am now ready to reconstruct the argument from internal relatedness. The argument proceeds in two main stages. First, it is argued that all things are internally related in ways that render them interdependent. That is, no two things are freely recombinable. Second, the substantial unity of the universe is inferred from the interdependence of all of its parts. That is, failure of free recombination is the modal signature of an integrated monistic cosmos. I will start with the second stage and provide two formal proofs, from two sets of defensible assumptions.

I should say at the outset that I think the real action is at the first stage of the argument (Sect. 3). The second stage is hard to resist, and I know of no one in the literature (on either side) who questioned this stage. ${ }^{17}$ Still it may be interesting to see that there are multiple proofs available, and what assumptions they require. (I do not claim that the assumptions I provide are the only ones that will yield a proof, or even the most plausible ones - I only claim to provide proofs.)

\subsection{First proof}

For the first proof I assume the conceptual resources of first-order logic, plus classical mereology on a domain of actual concrete objects. Though weaker mereological systems will suffice. I will not for

\footnotetext{
17 That said, both McTaggart and Whitehead are pluralists who accept the internal relatedness of all things. To my knowledge neither explicitly says why they resist the monistic conclusion. Though in Whitehead's case it may well trace to the fact that he has a non-classical 'junky' mereology, without a maximal element (Simons 1987, p. 83). Whitehead would thus reject the Concrete Universe principle used in the proofs.
} 
instance need to assume universal fusion. Here are the specific mereological principles invoked in the first proof (note that all quantifiers from here on are restricted to actual concrete objects):

(Concrete universe) $\quad u={ }_{d f}(\iota x)(\forall y) y<x$

This tells us that we have a unique maximal element among concrete objects - a cosmos.

(Concrete weak If $x \ll y$ then $(\exists z)(z \ll y \& \neg \mathrm{O} z x)$ supplementation)

This tells us that any concrete object that has one concrete proper part must also have some other disjoint concrete proper part.

Here are the three assumptions that drive the first proof:

(Assumption 1) No two things are modally free:

$$
(\forall x)(\forall y) \neg \mathrm{M}^{2} x y
$$

This is the key assumption. It is what is to be established in the first stage of the argument (Sect. 3), when it is to be argued that all things are internally $y_{\text {constraining }}$ related (an internal constraining $_{\text {relation is precise- }}$ ly one that entails lack of modal freedom: Sect. 1.3).

(Assumption 2) There is something basic: $(\exists x) \mathrm{B} x$

Given the restricted quantifiers, this is not the assumption that there is something fundamental, but only the assumption that there is some concrete object that is not dependent on any other concrete object. This is the denial of priority nihilism (Sect. 1.1). What is ruled out is the prospect of limitlessly descending chains of priority in the concrete realm.

$$
\begin{array}{ll}
\text { (Assumption 3) } & \text { Any basic thing will be modally free of } \\
& \text { anything it does not overlap: } \\
& (\forall x)(\forall y)\left((\mathrm{B} x \& \neg \mathrm{O} x y) \rightarrow \mathrm{M}^{2} x y\right)
\end{array}
$$

This assumption links the metaphysical status of basicness, the mereological notion of overlap, and the modal notion of independence. It is motivated by the following combinatorialist intuition. Suppose $x$ is a basic entity. Then it is ontologically independent. If there is some $y$ that it does not overlap, then $x$ and $y$ are mereologically independent. But now there seems to be nothing to tie $x$ and $y$ together across worlds, so there should be no barrier remaining to free recombination. (In particular what is ruled out - from $x$ 's being basic - is that $x$ and $y$ are tied together by co-depending on a larger whole.) Another way to put this point: failures of free recombinability need explanation, and there are two possible sorts of 
explanation, having a common part (overlapping), and having a common ground (co-dependence). If neither obtains, then no linkage remains to ground any modal constraints.

The proof itself is trivial, and I will intersperse only the briefest commentary:

(Stage 2, proof 1)

(1) $(\exists x)(\mathrm{B} x \& x \ll u) \quad$ Supposition (for reductio)

(2) $\mathrm{B} a \& a \ll u \quad 1, \exists \mathrm{I}$

We begin by supposing for reductio that something short of the whole cosmos is basic. Call that $a$.
(3) $\quad(\exists x) \neg \mathrm{O} a x$
(4) $\neg \mathrm{O} a b$
2, weak supplementation
3, $\exists \mathrm{I}$

Since $a$ is short of the whole cosmos, there must be something else in the cosmos that $a$ does not overlap. Call that $b$.
(5) $\mathrm{M}^{2} a b$
(6) $\neg \mathrm{M}^{2} a b$
2, 4, Ass. 3, UI, MP
Ass. 1, UI

By Assumption 3, $a$ and $b$ are modally free. Yet by Assumption 1 nothing is. Contradiction.

(7) $\neg(\exists x)(\mathrm{B} x \& x \ll u) \quad 1-6,5,6$, reductio

(8) (ᄏ!x) $\mathrm{B} x \& \mathrm{~B} u \quad$ Ass. 2, 7, def. $u$

Nothing short of the whole cosmos is basic, and Assumption 2 tells us something must be basic, so the only possibility is that the whole cosmos is the one and only basic entity. That is priority monism.

What is so special about the universe? From the perspective of this first proof, what is special about the universe is that it is the only thing to have the status of overlapping everything: $(\forall x) \mathrm{O} u x$. Thus $u$ is the only thing for which the antecedent of Assumption 3 cannot be instantiated.

\subsection{Second proof}

I offer a second proof of the second stage of the argument from internal relatedness, using weaker assumptions but heavier mereological principles. The specific mereological principles invoked are as follows (here again, all quantifiers remain restricted to actual concrete objects):

(Concrete universe) $\quad u={ }_{d f}(\mathrm{\iota} x)(\forall y) y<x$ 
Again we have a unique maximal element among concrete objects - a cosmos.

$$
\begin{array}{r}
\text { (Concrete } \\
\text { complementation) }
\end{array} \quad \hat{x}=_{d f}(\iota y)(\forall z)(z<y \leftrightarrow \neg \mathrm{O} z x)
$$

This tells us that for any individual $x$ we can find another individual $\hat{x}$ (the complement of $x$ ), where $\hat{x}$ is the rest of the cosmos without $x$. This is a fairly heavy mereological principle in that those uncomfortable with the gerrymandered individuals universal fusion produces may feel a like discomfort with the individuals complementation produces. Most mereologists would agree that a given table is an individual. But consider the complement of the table (the universe minus the table). That might not seem a very unified thing, and it certainly is not the sort of thing that English has a ready sortal for.

The second proof will be driven by two assumptions:

$$
\begin{array}{ll}
\text { (Assumption 1) } & \text { No two things are modally free: } \\
& (\forall x)(\forall y) \neg \mathrm{M}^{2} x y
\end{array}
$$

Again we have the key assumption, which follows directly from the internal $_{\text {constraining }}$ relatedness of all things (Sect. 3).

(Assumption 4) Non-overlapping, modally constrained things are interdependent:

$$
(\forall x)(\forall y)\left(\left(\neg \mathrm{O} x y \& \neg \mathrm{M}^{2} x y\right) \rightarrow \mathrm{I} x y\right)
$$

This assumption links the mereological notion of overlap, the modal notion of independence, and the metaphysical status of interdependence (recall that interdependent entities are those that each depend on a greater common whole, like multiple arms of one Aristotelian organism: Sect. 1.2). It is motivated by a similar combinatorialist intuition as motivated Assumption 3 (Sect. 2.1). The idea now is that if you have two mereologically independent entities $x$ and $y$ that are modally linked, it must be because they are co-dependent upon a common ground $z$. But $z$ must contain both $x$ and $y$ as parts, for if there were any portion of $x$ or $y$ outside of $z$, $z$ would not 'contain enough reality' to ground the left out portion.

The proof itself is a bit longer, though still relatively trivial:

(Stage 2, proof 2)
(1) $\neg \mathrm{B} u$
Supposition (for reductio)
(2) $(\exists x) \mathrm{D} u x$
1, def. $\mathrm{B}$
(3) Dua
2, $\exists \mathrm{I}$ 
We first suppose for reductio that the cosmos is not basic. That means that the cosmos must be dependent on something - call it $a$.
(4) $\neg \mathrm{Dau}$
3, asymm. $\mathrm{D}^{18}$

Since dependence is asymmetric, a cannot be dependent on the cosmos.
(5) $a \ll u$
3, irreflex. D, def. $u$

Since dependence is irreflexive, $a$ cannot be the cosmos, and since everything else is a proper part of the cosmos, so is $a$.
(6) $\neg \mathrm{M}^{2} a \hat{a}$
5. Ass. 1

We find $a$ 's complement $\hat{a}$, and note that $a$ and $\hat{a}$ are not modally free by Assumption 1.
(7) $\neg \mathrm{O} a \hat{a}$
def. complement
(8) $\mathrm{I} a \hat{a}$
6, 7, Ass. 4, UI, MP

Nothing overlaps its complement, so we can plug in Assumption 4 to show that $a$ and $\hat{a}$ are interdependent.
(9) Dau
8, def. I, def. $u$
(10) $\mathrm{B} u$
$1-9,3,9$ reductio

If $a$ and $\hat{a}$ both depend on a common whole, they must both depend on the cosmos since that is the only whole they have in common. Hence $a$ is dependent on the cosmos after all, which completes the reductio. The cosmos is basic.
(11) $(\exists x)(\mathrm{B} x \& x \ll u)$
Supposition (for reductio)
(12) $\mathrm{B} b \& b \ll u$
11, $\exists \mathrm{I}$

We now suppose for reductio that something else (which would have to be a proper part of the cosmos) is basic - call it $b$.
(13) $\neg \mathrm{M}^{2} b \hat{b}$
12, Ass. 1, def. u
(14) $\neg \mathrm{O} b \hat{b}$
def. complement
(15) $\mathrm{I} b \hat{b}$
13, 14, Ass. 4, UI, MP

\footnotetext{
${ }^{18}$ One could also infer (4) from an anti-symmetric conception D, coupled with the natural modification of basicness: $x$ is basic ${ }_{d f} \neg(\exists y)(x \neq y \&$ D $x y)$ (Sect. 1.2). In line two one would infer $(\exists x)(x \neq u \& D u x)$, line three would read $a \neq u \& D u a$, and the rest of the proof would follow as written.
} 
Mirroring the inference of (6)-(8), we infer the interdependence of $b$ and $\hat{b}$.
(16) $(\exists x) \mathrm{D} b x$
15, def. I
(17) $\neg \mathrm{B} b$
16, def. B
(18) $\neg(\exists x)(\mathrm{B} x \& x \ll u) \quad 11-17,12,17$, reductio

If $b$ is interdependent then it is dependent and not basic after all, which completes the reductio. Nothing other than the cosmos is basic.

(19) $(\exists ! x) \mathrm{B} x \& \mathrm{~B} u \quad$ 10, 18 , def. $u$

Pasting our two reductios together, we have the priority monistic conclusion that the whole cosmos is the one and only basic entity.

What is so special about the universe? From the perspective of this second proof, what is special about the universe is that it is the only thing with no complement (the universe minus itself would be nothing, and classical mereology tolerates no null individual). Thus $u$ is the only thing that cannot be shown interdependent with its complement.

Let me say a bit more about what I think has been done so far. I have proved - on the key assumption that no two things are modally free, and some plausible combinatorialist assumptions about how basic things should be modally free - that only the whole can be

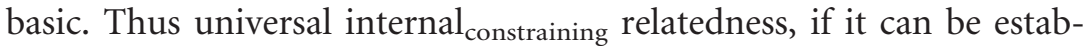
lished, would reveal an integrated monistic cosmos.

\section{Stage one: universal internal relatedness}

It remains to consider the first stage of the argument from internal relatedness, where it is argued that all things are internally related. More precisely, the issue is whether all things are internally constraining $_{\text {. }}$ related (Sect. 1.3), as per Assumption 1 of both proofs (Sect. 2). I will argue that there are several plausible contemporary views that vindicate Assumption 1. Given the key idea of standing the Humean principle of free recombination on its head, some of the views I cite may not be surprising. Views that reject free recombination (such as various non-Humean views) will vindicate the key neo-Hegelian premiss. (I do not claim that the views I cite are the only ones that will vindicate the key premiss, or even the most plausible ones - I only claim to cite some defensible views.) 


\subsection{The axiom of internal relations}

To begin with, it is crucial to notice that there are at least two different general strategies for trying to vindicate Assumption 1. The first strategy runs as per the following schema (plug any conception of internality in for $x$ ):

(First strategy)

(i) All things are related

(ii) All relations are internal ${ }_{x}$ relations

(iii) Thus all things are internally $y_{x}$ related

The historical debate tended to focus on this first strategy, and it was not without its supporters. ${ }^{19}$ Premiss (ii) - sometimes called 'the axiom of internal relations' - served as Russell and Moore's target. Thus Moore spoke of undermining 'the dogma that all relations are internal' (1919, p. 50), and subsequent histories would tell the tale of how Russell and Moore refuted monism by establishing the existence of external relations on commonsensical grounds.

But consider a second strategy, which uses the following schema:

(Second strategy)

(iv) All things are related by relation $\mathrm{R}$

(v) $\mathrm{R}$ is an internal relation

(vi) Thus all things are internally $y_{x}$ related

Schema (iv)-(vi) yields the same conclusion as schema (i)-(iii), but allows that there can be external relations. It only requires there to be at least one internal relation, pervasive enough to connect all things. ${ }^{20}$ Thus Bradley (though not generally an advocate of the argument from internal relatedness: Sect. 1.3) explains how Russell and Moore missed the point:

The most that it could show would be that some relations are external and may make no difference to their terms. But to argue from this that all the relations are or even may be external, and that some qualities either do or may exist independently, seems quite illogical. (Bradley 1897, p. 513)

\footnotetext{
19 For instance Bosanquet writes (1911, p. 278): 'Relations are true of their terms. They express their positions in complexes, which positions elicit their behavior, their self-maintenance in the world of things. This is really the all-important argument.'

${ }^{20}$ Strictly speaking even less may be required. A plurality of partially pervasive internal relations could wind up linking everything together through internal relation chains.
} 
So here is the third respect in which the argument from internal relatedness has been misunderstood: the argument is compatible with the existence of external relations, when pursued via this second strategy.

Thus the crucial question for the argument - when pursued via the second strategy - is not whether there are any external relations, but rather whether there are any decent candidates for a pervasive internal relation. This would be a relation that can serve as relation $\mathrm{R}$ in (iv) and (v), with $x=$ constraining. I will be arguing that there are several plausible contemporary metaphysical views that entail the existence of such a relation.

\subsection{Causal connectedness (given causal essentialism)}

One plausible candidate for a pervasive internal relation is causal connectedness, given the understanding of causation found in causal essentialism, and assuming some level of determinism. By causal connectedness, I mean the relation that obtains between any two things when there is a causal path (ignoring the direction of causation, and potentially running through intermediaries) from an event in which the one thing features to an event in which the other thing features. For instance, if two fragments are produced from one explosion, then one can find a causal path as follows: trace back from an event in which the one fragment features to the event of the explosion, and then trace forward from the explosion to an event in which the second fragment features.

Causal connectedness has good claim to be a pervasive relation, given those versions of Big Bang cosmology on which the Big Bang is a physically real event. For any two given actual concrete objects $a$ and $b$, there will be a causal path running from an event in which $a$ features back to the Big Bang, and then from the Big Bang forward to an event in which $b$ features. In the Big Bang cosmology, everything is a fragment of one primordial explosion. ${ }^{21}$

Causal connectedness can also lay claim to being an internal $\mathrm{l}_{\text {constraining }}$ relation, given causal essentialism. By causal essentialism, I mean the claim that individuals bear their causal powers and

\footnotetext{
${ }^{21}$ Strictly speaking causal connectedness only relates non-overlapping things. But overlap-

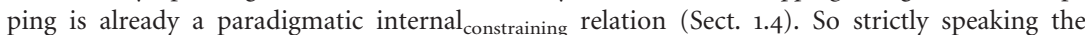

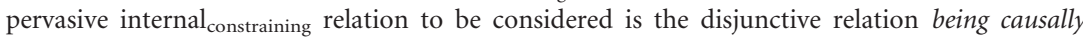
connected or overlapping. In the main text I will just speak of causal connectedness to simplify matters.
} 
liabilities essentially. ${ }^{22}$ Views in this vicinity have been defended by Shoemaker 1980, Swoyer 1982, Mumford 1998 and 2004, Ellis 2001, Heil 2003, and Bird 2007, inter alia. Such a claim might (though it need not) be understood as deriving from the following two essence claims. First, things fall under certain natural kinds essentially. For instance, a given electron will be said to fall under the natural kind being an electron essentially (Ellis 2001, pp. 6 and 127). Second, natural kinds confer certain causal powers and liabilities essentially. For instance, if being an electron confers the causal power to attract positively charged things and the liability to be attracted by positively charged things, then it confers these essentially (Ellis 2001, pp. 22 and 31).

Given causal essentialism, causal connectedness will impose modal constraints, since causal connectedness will generate necessary connections (on the assumption that some level of determinism holds). Recall that it is a necessary condition on modal freedom, that for any way that the one entity can be, and any way that the other entity can be, there is a world that realizes this combination (barring co-location, and leaving the remainder of the world as is). Now let $a$ and $b$ be two electrons never mind how distant in space-time these might be. Draw up the list of ways that $a$ can be. Perhaps $a$ cannot vary its intrinsic nature, but it should be able to vary its location, and at any rate there will be the one way that $a$ can fail to be. (Electrons are not necessarily existing beings!) Likewise draw up the parallel list of ways that $b$ can be. Now consider combination pairs involving any variation to the location or existence of $b$, such as $<a$ is as it actually is, $b$ is elsewhere $>$, or $<a$ is as it actually is, $b$ does not exist $>$. What results - leaving the remainder of the world as it actually is - is a causally incoherent scenario. For $b$ is enmeshed in chains of cause and effect. Relocating $b$ leaves a rip in the causal network, and deleting $b$ entirely leaves a hole in the causal network. Either would require there to be different causal powers and liabilities in the world (given determinism). ${ }^{23}$ And this is

\footnotetext{
${ }^{22}$ For the use I am putting causal essentialism to here, it is not required that all things bear their causal powers and liabilities essentially. It is only required that all things that have a claim to being basic bear their causal powers and liabilities essentially. For things that have no claim to being basic are already dependent entities.

${ }^{23}$ If the causal system is radically indeterministic, permitting any outcomes at all, then the causal powers and liabilities need not differ. But as long as there are any restrictions, there will be recombinations of $a$ and $b$ that yield causal incoherencies. For instance, given the various conservation laws that seem to hold at our world, there will almost certainly be recombinations that are inconsistent with these laws.
} 
incompatible with the continued existence of either $a$ or $b$, as both bear their causal powers and liabilities essentially. The causal transactions running through $b$ - and in general the whole rest of the world - must be right to accommodate $a$. And so all things have relational requirements. The rest of the world must preserve the right causal pattern to accommodate their natures. Thus I offer the following instantiation of schema (iv)-(vi), in defence of Assumption 1:

(Second strategy, causal connectedness)

(1) All things are related by causal connectedness

(2) Causal connectedness is an internal constraining $_{\text {relation (given }}$ causal essentialism)

(3) Thus all things are internally $y_{\text {constraining }}$ related

Indeed, several classical monists (including Lotze (1892, p. 39), Blanshard (1962, p. 472), and Ewing (1934, pp. 183-7)) endorsed something akin to this argument to vindicate universal internal relatedness. Thus Blanshard claims that 'all things and events are inter-related necessarily', such being 'the cosmic implications of causality' (1962, p. 472). Ewing explicitly warns that 'realist and pluralist critics have not paid sufficient attention to the fact that there is at least one all-pervasive relation [namely causality] which makes a difference to its terms in a very real sense' $(1934$, p. 183), and goes on to conclude:

We have thus as a result of our considerations of causality reached the conclusion that the world known by us constitutes a system in which every particular is linked to the rest of the system... [T] he nature of any one thing taken by itself is incomplete and internally incoherent without the whole system on which it depends. Things by their very essence belong together. (1934, p. 187)

I should also note that some causal essentialists have perceived the holistic character of their metaphysic, albeit perhaps without hearing the echo of the argument from internal relatedness. Thus Ellis, echoing Hume's pluralistic talk of loose and separate events, notes:

The essentialist's world is therefore not one in which all events are loose and separate. On the contrary, it is a world dominated by causal powers in which events activating these powers necessitate other events that are their displays... The essentialist's world is therefore a bound and connected world. (2001, p. 287) 
In a similar vein, Mumford holds that causal essentialism indicates a holistic view of the world ... a property cannot stand alone, unaffected by and unconnected with anything else. A world comes with a whole, connected system of properties' (2004, p. 182).

3.3 Spatiotemporal relatedness (given structuralist supersubstantivalism) A second decent candidate for a pervasive internal relation is spatiotemporal relatedness, given the understanding of space-time found in structuralist supersubstantivalism. By spatiotemporal relatedness I simply mean the relation of belonging to a common spatiotemporal system. I take it to be obvious that this relation has good claim to be a pervasive relation.

By structuralist supersubstantivalism I mean the combination of (i) the supersubstantivalist thesis that actual concrete objects are identical to regions of space-time, with (ii) the structuralist thesis that space-time regions possess their distance relations essentially. The supersubstantivalist thesis is endorsed by Descartes and Spinoza, as well as Quine (1981, p. 17), Lewis (1986, p. 76), Sider (2001, p. 110), Skow (2005), and Schaffer (2009b). As Descartes puts the view: 'There is no real distinction between space,... and the corporeal substance contained in it; the only difference lies in the way in which we are accustomed to conceive of them' (1985, p. 227). The structuralist thesis - which emerged as an answer to the Einstein-Earman hole argument (Ladyman and Ross 2007, pp. 141-5; Esfeld and Lam 2008) - holds that the essence of any given region is at least partly determined by its network of interrelations with other regions.

Given structuralist supersubstantivalism, the spatiotemporal distance relations between any two things will be essential to them, since the things are regions, and the distance relations are essential to the regions. So when we consider the ways that a given entity $a$ can be, perhaps a cannot vary its location, but it should be able to vary its intrinsic nature, and at any rate there will be the one way that $a$ can fail to be. So with two given entities $a$ and $b$, consider combination pairs involving the one remaining as it actually is, with the other failing to be, such as: $<a$ is as it actually is, $b$ does not exist $>$. What results leaving the remainder of the world as it actually is - is a spatiotemporally incoherent scenario. For $a$ is what it is in virtue of its place in the spatiotemporal structure. Simply deleting $b$ from the world leaves a hole in the spatiotemporal manifold, which is incompatible with the 
continued existence of $a$, as $a$ bears its totality of spatiotemporal relations essentially. ${ }^{24}$ The spatiotemporal network running through $b$ - and in general the whole rest of the world - must be right to accommodate $a$. And so all things have relational requirements. The rest of the world must preserve the right spatiotemporal structure to accommodate their natures. ${ }^{25}$ So here is a second instantiation of schema (iv)-(vi), in defence of Assumption 1:

(Second strategy, spatiotemporal relatedness)

(1) All things are related by spatiotemporal relatedness

(2) Spatiotemporal relatedness is an internal constraining $_{\text {relation }}$ (given structuralist supersubstantivalism)

(3) Thus all things are internally $y_{\text {constraining }}$ related

Historically, the connection between supersubstantivalism and monism was drawn by Spinoza. In this vein, Kant admitted that space is 'essentially one', since 'these parts cannot precede the one all-embracing space, as being, as it were, constituents out of which it can be composed; on the contrary, they can be thought only as in it' (Kant 1787, p. 69). He thus concluded that the only escape from Spinozistic monism was to declare the unreality of space and time (!):

[I]f this ideality of time and space is not adopted, nothing remains but Spinozism, in which space and time are essential attributes of the Supreme Being Himself, and the things dependent on Him (ourselves, therefore, included) are not substances, ... (Kant 1788, p. 108)

I should also note that some structuralists have perceived the holistic character of their metaphysic, albeit perhaps without hearing the echo of the argument from internal relatedness. Thus Esfeld and Lam maintain that it is physically meaningless to consider a space-time point independently of the space-time structure and in particular

\footnotetext{
${ }^{24}$ Analogy: for the mathematical structuralist, if per impossibile the number six were not to exist, then the number two could not exist either, because to be the number two a thing has to be related in the right ways to the number six.

25 There is some irony in this result, in that spatiotemporal relations were precisely what Moore trotted out as his paradigm examples of external relations. In this respect it may be interesting to compare the argument given in the main text with Bradley's response to Moore:

If ... you take a billiard-ball and a man in abstraction from place, they will of course - so far as this is maintained - be indifferent to changes of place. But on the other hand neither of them, if regarded as so, is a thing which actually exists; each is a more or less valid abstraction. But take them as existing things and take them without mutilation, and you must regard them as determined by their places and qualified by the whole material system in which they enter. (1897/1978, p. 517)
} 
independently of the space-time relations that define its position in the network' (2008, p. 37), and hold an interdependence thesis on which 'we get the relata and the relations at once as the internal structure of a whole' (2008, p. 34). And Shapiro-discussing mathematical structuralism - notes explicitly the holistic consequences of any sort of structuralist view:

The structuralist vigorously rejects any sort of ontological independence among the natural numbers. The essence of a natural number is its relations to other natural numbers. The subject-matter of arithmetic is a single abstract structure,... The number 2 is no more and no less than the second position in the natural number structure; and 6 is the sixth position. Neither of them has any independence from the structure in which they are positions, and as positions in the structure, neither number is independent of the other. (2000, p. 258)

Any sort of structuralist view of the proper parts of the world (including causal essentialism, which may equally be called causal structuralism) has monistic consequences.

\subsection{Being worldmates (given counterpart theory)}

The third decent candidate for a pervasive internal constraining $_{\text {relation is }}$ being worldmates, seen through the lens of counterpart theory. All actual concrete objects are worldmates, and so this relation is evidently pervasive. What I will now argue is that it is internally constraining, given counterpart theory. What I specifically have in mind is postulate $\mathrm{P}_{2}$ of Lewisian counterpart theory, which says that all entities are worldbound entities, and which Lewis glosses as: 'Nothing is in two worlds' (1968, p. 114).

So consider any two given actual concrete objects $a$ and $b$. Given the worldboundness thesis of counterpart theory, there is only one world at which $a$ is found (namely, actuality), and likewise only one world at which $b$ is found. So for the ways associated with $a$ one only finds $W_{a}=\{a$ is as it actually is, $a$ does not exist $\}$, and likewise for the ways associated with $b$ one only finds $W_{b}=\{b$ is as it actually is, $b$ does not exist $\}$. So now consider the following two combination pairs in $W_{a} \times W_{b}:<a$ is as it actually is, $b$ does not exist $>$ and $<a$ does not exist, $b$ is as it actually is $>$. These combination pairs have no realizing worlds, for they describe modally incoherent scenarios. For if either of these entities is as it actually is, we can only be looking at the actual world, since this is the only world where either of these entities is at all. But if we are looking at the actual world then the other entity exists after all. In other words, deleting either entity from the world 
must take us to a different world where the other entity is not to be found. The world to which a given entity is bound turns out be a necessary accompaniment to that entity. Thus I offer the following instantiation of schema (iv)-(vi), in defence of Assumption 1:

(Second strategy, counterpart theory)

(1) All things are related by being worldmates

(2) Being worldmates is an internal constraining $_{\text {relation (given }}$ counterpart theory)

(3) Thus all things are internally $y_{\text {constraining }}$ related $^{26}$

Three points of clarification may be helpful. First, one may compare the counterpart theorist's metaphysics to the metaphysics of the hyper-essentialist, who holds that every single feature of an entity is essential to it (and $a$ fortiori holds that every single relation is essential to its relata, as per the very strong notion of internal essential $_{\text {related- }}$ ness). The hyper-essentialist looks over her worlds and (assuming that all worlds are discernible) sees no individual at more than one world. For if she sees some individual $x$ at a world $w$, then she will see $x$ as essentially having the property of being in a world with the distinctive features of $w$. In this respect the counterpart theorist has exactly the same picture of the worlds as the hyper-essentialist.

The counterpart theorists and the hyper-essentialist merely have a semantic dispute, as to how to interpret claims in the modal language against their shared metaphysical picture. The hyper-essentialist treats claims such as 'I could be sleeping now' as false. But the counterpart theorist is a contextualist about these claims, treating their truth conditions in terms of whether someone similar to me in contextually salient respects is sleeping now. Just do not confuse the semantics with the metaphysics. Metaphysically, the counterpart theorist has exactly the same picture as the hyper-essentialist. The counterpart theorist merely offers a clever way of using the modal language to make the metaphysical picture more palatable.

As a second point of clarification, I should acknowledge that, while the counterpart theorist cannot recognize a realizing world for

\footnotetext{
${ }^{26}$ Indeed, counterpart theory even vindicates schema (i)-(iii), on even the strongest relevant conception of internality as internal $l_{\text {essential }}$ (Sect.1.3)! Take any two entities $a$ and $b$, and any relation $R$ holding between them. Then we have, at all worlds, ( $a$ exists $\leftrightarrow \mathrm{R} a b) \&$ ( $b$ exists $\leftrightarrow \mathrm{R} a b$ ), since we have ( $a$ exists \& $b$ exists \& Rab) at actuality, and none of these conjuncts holding at any other world.
} 
combinations such as $<a$ is as it actually is, $b$ does not exist $>$, she can at least (in some contexts) recognize a representing world for these combinations. For instance, she can recognize a world with one and only one thing $c$ that is an intrinsic duplicate of $a$ but not of $b$. And she can recognize a context in which intrinsic duplication is the one and only relevant respect of similarity. Then in such a context she will recognize a world that represents $<a$ is as it actually is, $b$ does not exist $>$. For in such a context it will be by her lights true to say it is possible for $a$ to be as it actually is and for $b$ not to exist'.

But the existence of a representing world is not enough for modal freedom, for two reasons. First, a residue of modal constraint remains. There is still no realizing world for certain combinations. This is something that needs explaining. Why, one should ask the counterpart theorist, are individuals bound to their worlds? In other words, what is the metaphysical basis for Lewis's postulate $\mathrm{P} 2$ ? Here is what I take to be a good answer: the reason an individual is bound to its world is that the individual is a dependent fragment of that world. But that is the monistic answer.

The second reason why the existence of a representing world is not enough is that the existence of a representing world is a contextdependent matter. As such this matter is unsuited for real metaphysical work, assuming that the dependence structure of the world is not a context dependent matter. (The counterpart theorist who holds otherwise is then thinking of dependence as context relative, and should treat it as a three-place relation Dxyz. She might still be interested in which contexts yield the pluralistic image of a scattering of dust, and which lead to the monistic image of a unified cosmos (Sect. 1.2).)

As a third point of clarification, it might seem implausible with charging Lewis with imposing drastic limits on modal freedom, given that he is one of the foremost advocates of free recombination. But Lewis and I are just using 'free recombination' differently. Lewis begins with the following intuitive idea: ' $[\mathrm{A}]$ nything can coexist with anything else... Likewise, anything can fail to coexist with anything else' (1986, p. 88). He then has two main ways to interpret this idea in his system. In the extensional language of quantification over worlds, this idea comes out false (given worldboundness). It is false that there is a world in which I coexist with a unicorn, because the only world where I exist is the actual world, and the actual world is unicorn-free. In the intensional modal language this idea comes out context dependent - and only true in the laxest of contexts in which anti-essentialism operates. For instance, it is only true to say 'I can 
coexist with a unicorn' in contexts in which the property of being at a unicorn-free world is not a salient enough respect of similarity to restrict counterparthood. Lewis notes these problems (1986, pp. 88-9), and in response offers a third interpretation of the original intuitive idea in terms of duplicates: 'Instead, I should say that a duplicate of the dragon and a duplicate of the unicorn coexist at some world' (1986, p. 89). This is the only sense of recombination that Lewis aims to sustain.

Lewis's resulting duplication-based notion of free recombination is a perfectly coherent notion, and one that he then uses to do interesting work. In particular it allows him to rule certain scenarios as being possible. I have no objection to this notion. Only I would add that there is another perfectly coherent notion of free recombination, involving the extensional language of quantification over worlds, and with respect to which Lewis acknowledges imposing drastic limits on modal freedom (1986, p. 88). ${ }^{27}$ I have argued that this notion can do interesting work too. In particular it can vindicate the key neo-Hegelian premiss.

Historically, several classical monists argued from a hyperessentialist metaphysical picture. As Joad summarizes the view, '[U]nless a hen's egg were smaller than an emu's, unless it were browner than a pigeon's and larger than a sparrow's, unless it were more brittle than rubber and more oval than a billiard ball, it would not be the egg that it is' (1936, p. 414). And so:

[E]verything in the universe is bound up with everything else in a network of relations which ... penetrate into their being and make them what they are. Change a thing and you change its relations; you change, therefore, everything in the universe. Change the relations of a thing and you change the thing. The universe, on this view, may be likened to an enormous reverberating chamber, in which any whisper, however faint, in any part, however remote, echoes and re-echoes throughout the whole. (Joad 1936, pp. 414-15)

\footnotetext{
27 To see how different Lewis's notion of free recombination is from the notion I am using, consider the case of overlap. On the notion of free recombination I am using, overlap is a

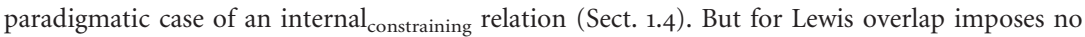
constraints. If $a$ and $b$ overlap - at least in the case where neither is part of the other - there can be a duplicate of either without a duplicate of the other. Also consider the case where $a$ 's being red modally entails $b$ 's being blue. On the notion of free recombination I am using, this is a clear modal constraint as to how these two entities are. But for Lewis this case imposes no constraints either.
} 
To the extent that the counterpart theorist accepts this metaphysical picture but merely alters the semantics of modal discourse, she agree with the metaphysics of the classical monist in this crucial respect. It may be instructive - with counterpart theory in mind - to return to the following passage from Baylis:

Realists have tried to escape the doctrine of the internality of relations by making a distinction between all the predicates or characters of a term, ... and its essential characters ... To this, advocates of the internality of relations reply that all the characters of any entity are essential to it. An entity with even one different character is ipso facto not the same entity. But, the realists say, it is essentially the same, to which the idealists reply that it is very similar... And so another impasse is reached and the argument degenerates into a disagreement as to the validity of the distinction between essence and accident. (Baylis 1929, p. 373)

I thus conclude that causal essentialism, structuralist supersubstantivalism, and counterpart theory all vindicate the crucial neo-Hegelian premiss that all things are internally constraining $_{\text {related. I should empha- }}$ size that I have not defended any of these three positions here, but merely forwarded them as plausible. I have also not suggested that these are the only three positions that vindicate the crucial neo-Hegelian premiss. Other positions to consider include resemblance views of properties on which things have their sparse properties essentially, and these sparse properties are constituted by global resemblance patterns (as per resemblance nominalism and classical trope theory); and also theistic views on which all things are essentially parts of God's creation.

\section{Concluding fragments}

Summing up: I have maintained that the argument from internal relations, properly understood, is at least plausible and may even be sound. This involved correcting three main misunderstandings of the argument:

- It is not an argument for a world-only metaphysic, but for a world-first metaphysic (Sect. 1.1)

- It does not require implausibly strong claims about relational essences, but only a denial of Humean free recombination (Sect. 1.3) 
- It is compatible with the existence of external relations, so long as there are also internal relations pervasive enough to connect all things (Sect. 3.1)

I have only considered priority monism as a claim about actuality (Sect. 1.1). The full modal status of the argument depends on the status of the premisses. Assumptions 2-4 all have some claim to hold with metaphysical necessity. But the modal status of Assumption 1 depends on how it is defended. For instance, if Assumption 1 is defended from the counterpart-theoretic claim of worldboundness, then it has claim to metaphysical necessity as well. But if Assumption 1 is defended from the claim that all things are causally connected, then it may not have claim to metaphysical (or even nomological) necessity. The causal defence of Assumption 1 is at least consistent with the existence of causally disconnected pluralistic worlds.

What would it take for the pluralist to block the argument? Evidently she will need to deny at least one of the assumptions or mereological principles used in the two arguments for monism in section 2. I take it that her two most promising options are:

- Defend free recombination, and thus reject Assumption 1

- Posit brute modality, so as to reject Assumptions 3 and 4

I consider both options to be open, and have no knock-down arguments against either. To compare the monistic view to the sort of pluralism that defends free recombination is to engage in the further dispute over the three views discussed in sections 3.2-3.4. I cannot engage in this dispute here but would note that many contemporary metaphysicians endorse at least one of the three doctrines discussed.

To compare the monistic view to the sort of pluralism that posits brute modality is to engage in the further dispute over whether modal features must ultimately be grounded in the categorical (Sider 2001, pp. 40-2). I consider brute modality something to be avoided if possible, but obviously cannot defend that position here either. I would only note that many contemporary metaphysicians endorse this position too.

Pending arguments against the monistic view, and assuming at least one of the three views discussed in sections 3.2-3.4, monism claims the heady advantage of explaining the modal constrains between all things 
without recourse to brute modality. I have elsewhere (Schaffer 2010) defended priority monism as best fitting the quantum mechanical image of an entangled cosmos, and as best accommodating the empirically open possibility of gunk. So I hereby add a third argument to the repertoire: priority monism best explains the modal constraints between all things.

A paper defending the internal relatedness of all things ought to wax poetical in conclusion. Rather than subject the reader to my fumblings, I leave her in the skilled hands of Elizabeth Barrett Browning:

And truly, I reiterate, nothing's small!

No lily-muffled hum of a summer-bee,

But finds some coupling with the spinning stars;

No pebble at your foot, but proves a sphere;

No chaffinch, but implies the cherubim;

And (glancing on my own thin, veinèd wrist)

In such a little tremour of the blood

The whole strong clamour of a vehement soul

Doth utter itself distinct. Earth's crammed with heaven,

And every common bush afire with God.

(Aurora Leigh, VII.I.812-26) ${ }^{28}$

\section{References}

Aristotle Cat.: 'Categories'. In Barnes 1984, pp. 3-24.

— Meta.: 'Metaphysics'. In Barnes 1984, pp. 1552-728.

Armstrong, David 1997: A World of States of Affairs. Cambridge: Cambridge University Press.

Aurelius, Marcus Med.: Meditations, trans. George Long. Mineola, NY: Dover, 1997.

Barnes, Jonathan (ed. and trans.) 1984. The Complete Works of Aristotle, vols. 1 and 2. Princeton, NJ: Princeton University Press.

Baylis, Charles 1929: 'Internality and Interdependence'. Journal of Philosophy, 26, pp. 373-9.

Bird, Alexander 2007: Nature's Metaphysics: Laws and Properties. Oxford: Clarendon Press.

\footnotetext{
${ }^{28}$ Thanks to Karen Bennett, Phillip Bricker, David Chalmers, Louis de Rosset, Maya Eddon, John Hawthorne, Hud Hudson, Kris McDaniel, Agustin Rayo, Raul Saucedo, Susanna Schellenberg, Brad Skow, Jessica Wilson, Mind's editor and referees, and audiences at Nature and its Classification (University of Birmingham, October 2007), Syracuse, MIT, ANU, Oxford, the 2008 AAP, and the Bellingham Summer Philosophy Conference (Western Washington University, August 2008).
} 
Bosanquet, Bernard 1911: Logic, or the Morphology of Knowledge, Vol. II, 2nd edition. Oxford: Clarendon Press.

Blanshard, Brand 1939: The Nature of Thought. London: Allen and Unwin.

-1962: Reason and Analysis. La Salle, IL: Open Court, rpnt 1973.

Bradley, F. H. 1897: Appearance and Reality: A Metaphysical Essay, 2nd edition. Oxford: Clarendon Press, rpnt 1978.

1935: Collected Essays. Oxford: Clarendon Press.

Bricker, Phillip 2006: 'The Relation between General and Particular: Entailment vs. Supervenience'. Oxford Studies in Metaphysics, 2, pp. 251-88.

Campbell, Keith 1990: Abstract Particulars. Oxford: Basil Blackwell.

Chalmers, David, David Manley, and Ryan Wasserman (eds) 2009: Metametaphysics. Oxford: Oxford University Press.

Church, Ralph 1935: 'On Dr. Ewing's Neglect of Bradley's Theory of Internal Relations'. Journal of Philosophy, 32, pp. 264-73.

Cottingham, John, Robert Stoothoff, and Dugald Murdoch (eds and trans) 1985: The Philosophical Writings of Descartes, vol. I. Cambridge: Cambridge University Press.

Descartes, Rene 1964: Principles of Philosophy. In Cottingham et al. 1985, pp. 177-292.

Edwards, Paul (ed.) 1967: The Encyclopedia of Philosophy, Vol. 7. New York, NY: Macmillan Company.

Ellis, Brian 2001: Scientific Essentialism. Cambridge: Cambridge University Press.

Esfeld, Michael and Vincent Lam 2008: 'Moderate Structural Realism about Space-time'. Synthese, 160, pp. 27-46.

Ewing, A. C. 1934: Idealism: A Critical Survey. London: Methuen.

- 1935: 'Reply: On Dr. Ewing's Neglect of Bradley's Theory of Internal Relations'. Journal of Philosophy, 32, p. 273.

Fine, Kit 1994a: 'Ontological Dependence'. Proceedings of the Aristotelian Society, 95, pp. 269-90.

1994b: 'Essence and Modality'. Philosophical Perspectives, 8, pp. $1-16$.

Gillett, Carl and Barry Loewer (eds) 2001: Physicalism and its Discontents. Cambridge: Cambridge University Press.

Guttenplan, Samuel (ed.) 1994: A Companion to the Philosophy of Mind. Oxford: Basil Blackwell.

Hamilton, Edith and Huntington Cairns (eds) 1961: The Collected Dialogues of Plato. Princeton, NJ: Princeton University Press. 
Hegel, G. W. F. 1817: The Encyclopedia of the Philosophical Sciences. In Hegel's Logic: Being Part One of The Encyclopedia of the Philosophical Sciences, trans. William Wallace. Oxford: Clarendon Press, 1975.

Heil, John 2003: From an Ontological Point of View. Oxford: Oxford University Press.

Hoffman, Joshua and Gary S. Rosenkrantz 1997: Substance: Its Nature and Existence. New York, NY: Routledge.

Hume, David 1748: An Enquiry Concerning Human Understanding, ed. Peter Millican. Oxford: Oxford University Press, 2007.

Joachim, Harold 1901: A Study of the Ethics of Spinoza: Ethica Ordine Geometrico Demonstrata. Oxford: Clarendon Press.

Joad, C. E. M. 1936: Guide to Philosophy. Mineola, NY: Dover, rpnt 1957.

Kant, Immanuel 1787: Critique of Practical Reason, trans. Norman Kemp Smith, $2^{\text {nd }}$ edition. New York, NY: St. Martin's Press, 1965. 1788: Critique of Practical Reason, trans. Thomas Kingsmill Abbott. Mineola, NY: Dover, 2004.

Ladyman, James and Don Ross 2007: Every Thing Must Go: Metaphysics Naturalized. Oxford: Oxford University Press.

Lewis, David 1968: 'Counterpart Theory and Quantified Modal Logic'. Journal of Philosophy, 65, pp. 113-26.

1986: On the Plurality of Worlds. Oxford: Basil Blackwell. 1994: 'Reduction of Mind'. In Guttenplan 1994, pp. 412-31.

Locke, John 1690: An Essay Concerning Human Understanding, ed. Kenneth P. Winkler. Indianapolis, IN: Hackett Publishing, 1996.

Loewer, Barry 2001: 'From Physics to Physicalism'. In Gillett and Loewer 2001, pp. 37-56.

Lotze, Hermann 1892: Outlines of a Philosophy of Religion, ed. F. C. Conybeare. London: Swan Sonnenschein and Co.

Lowe, E. J. 2005: 'Ontological Dependence'. Stanford Encyclopedia of Philosophy, [online encyclopedia], Fall 2009 edition, $<$ http://stanford.library.usyd.edu.au/archives/fall2009/entries/ dependence-ontological//>, accessed 3 November 2009.

Moore, G. E. 1919: 'External and Internal Relations'. Proceedings of the Aristotelian Society, 20, pp. 40-62.

Mumford, Stephen 1998: Dispositions. Oxford: Oxford University Press.

- 2004: Laws in Nature. London: Routledge.

Plato. Euth.: 'Euthyphro'. In Hamilton and Cairns 1961, pp. 169-85, trans. Lane Cooper. 
Rep.: 'Republic'. In Hamilton and Cairns 1961, pp. 575-84, trans. Paul Shorey.

Plotinus Enn.: The Enneads: London: Penguin Books 1991, ed. John Dillon, trans. Stephen MacKenna.

Proclus Comm.: Commentary on Plato's Parmenides. Princeton, NJ: Princeton University Press, 1987, trans. Glenn R. Morrow and John M Dillon.

Quine, W. V. O. 1981: 'Things and Their Place in Theories', in his Theories and Things. Cambridge, MA: Harvard University Press, pp. 1-23.

Rorty, Richard 1967: 'Relations, Internal and External'. In Edwards 1967, pp. 125-33.

Royce, Josiah 1900: The World and the Individual. New York, NY: Macmillan Company.

Schaffer, Jonathan 2007: 'Monism'. Stanford Encyclopedia of Philosophy, [online encyclopedia], Fall 2009 edition, <http:// stanford.library.usyd.edu.au/archives/fall2009/entries/monism/>, accessed 3 November 2009.

2009a: 'On What Grounds What'. In Chalmers et al. 2009, pp. $347-83$.

2009b: 'Spacetime the One Substance'. Philosophical Studies, 145, pp. $131-48$.

2010: 'Monism: The Priority of the Whole'. Philosophical Review, 119, pp. 31-76.

Shapiro, Stewart 2000: Thinking about Mathematics: The Philosophy of Mathematics. Oxford: Oxford University Press.

Shoemaker, Sydney 1980: 'Causality and Properties'. In van Inwagen 1980, pp. 109-35.

Sider, Theodore 2001: Four-Dimensionalism: An Ontology of Persistence and Time. Oxford: Oxford University Press.

Simons, Peter 1987: Parts: A Study in Ontology. Oxford: Oxford University Press.

Skow, Bradford 2005: 'Supersubstantivalism', in his Once Upon a Spacetime. Dissertation, New York University.

Spinoza, Benedict 1661[?]: 'Letter to Oldenburg', in his Letters to Friend and Foe, ed. Dagobert Runes, trans. R. H. M. Elwes. New York, NY: Philosophical Library, 1966.

Swoyer, Chris 1982: 'The Nature of Natural Law'. Australasian Journal of Philosophy, 6o, pp. 203-23.

van Inwagen, Peter (ed.) 1980: Time and Cause. Dordrecht: Reidel. - 2002: Metaphysics. Boulder, CO: Westview. 